\title{
Resenha: Atuação do Psicólogo no Campo Jurídico
}

\author{
Flávia de Novaes Costa ${ }^{1}$ \\ Tribunal de Justiça de Santa Catarina \\ Izabel Carolina Martins Campos \\ Secretaria de Administração do Estado de Santa Catarina \\ Roberto Moraes Cruz \\ Universidade Federal de Santa Catarina
}

\section{Book Review: The Work of the Psychologist in the Juridical Field}

O trabalho de psicólogos em organizações que visam à Justiça e a promovem é um campo de atuação relativamente novo, que necessita ser estudado para o aprimoramento dos serviços prestados à população. O livro Psicologia Jurídica no Brasil (Brandão \& Gonçalves, 2004) é uma demonstração do amadurecimento alcançado após décadas de trabalho de psicólogos no campo jurídico. Nele, a discussão sobre a interface das ciências psicológica e jurídica é aprofundada, além de serem evidenciadas contribuições que advém do conhecimento dos fenômenos psicológicos presentes no contexto jurídico.

Nos nove capítulos que constituem a publicação, as curiosidades e indagações abordadas, decorrentes de intervenções de psicólogos em organizações de Justiça, tais como: Tribunais, Fóruns de Justiça e Penitenciárias, impulsionam tanto os mais experientes quanto aqueles que, nesse campo, iniciam sua trajetória de estudos e de intervenção. Os leitores são convidados a conhecer aspectos da atuação de psicólogos em organizações de Justiça, os desafios enfrentados, os principais papéis por eles desempenhados, os tipos de demandas atendidas e as repercussões do seu trabalho nas instâncias jurídicas.

A necessidade de uma constante atualização no domínio de dispositivos legais básicos provenientes do Código Civil vigente, que contempla algumas das novas formas de configurações familiares, é enfatizada, especialmente aos psicólogos que atuam em Varas de Família. Dentre as diferentes modalidades de resolução de conflito caracterizados em tais Varas, é ressaltada a mediação familiar cujo objetivo maior é proporcionar aos envolvidos a possibilidade de autoria das decisões acerca de seus problemas.

A transformação das concepções em torno da adoção é estudada em capítulo específico, no qual, além da evolução histórica, é abordado o perfil das famílias adotantes, incluindo suas motivações e os principais aspectos de suas dinâmicas. A necessidade de revisão dos critérios estabelecidos pelas equipes profissionais é enfatizada, no sentido de incorporar mudanças sociais, bem como na utilização de uma postura avaliativa, mas que possibilite produzir efeitos pedagógicos.

Nas atividades desenvolvidas por psicólogos em organizações penais, as discussões apresentadas no livro tramitam

1 Endereço: Rua Antônio Ferreira, no 107, Centro Histórico, São José, SC, Brasil 88103-010. E-mail: flavianovaes_costa@ig.com.br em torno de aspectos psicossociais, com destaque para a necessidade da voluntariedade em qualquer tipo de "tratamento" e da contra-indicação de programas impostos de reinserção social. É feito um alerta para o fato de que as organizações prisionais têm dificuldades de cumprir a função de ressocialização, proporcionando efeitos punitivos freqüentemente desproporcionais ao crime cometido. Os profissionais também são lembrados de que o futuro das pessoas que cumprem pena está freqüentemente vinculado aos pareceres técnicos, fato que exige um constante exercício no sentido de avaliar sua atuação profissional.

No âmbito da infância e da juventude, além da importância do contexto histórico-cultural na visão a ele relacionada, distintos aspectos são focalizados. O abrigamento é uma alternativa evidenciada como sendo, repetidas vezes, a única forma de garantir a manutenção da integridade física e psicológica de crianças em situação de risco. As influências dos conceitos de "menor" e de "criança" nos dispositivos legais são analisadas, assim como as mudanças propostas e implementadas pelo Estatuto da Criança e do Adolescente - ECA - face ao adolescente em conflito com a lei. No trabalho desenvolvido junto a esses adolescentes, a proposta de intervenção remete, entre outras coisas, ao desenvolvimento da noção de responsabilidade social nos jovens e à análise do vínculo estabelecido com a infração, como forma de criar condições para a sua reinserção social.

A violência é abordada em dois artigos. No primeiro, são evidenciados as crianças e os adolescentes, sendo chamada atenção para a necessidade de compreensão da natureza dos eventos violentos e definida a violência de acordo com as diversas qualificações comumente utilizadas, quais sejam: física, sexual, psicológica, doméstica e intrafamiliar. Além disso, são analisadas as implicações das notificações de suspeita e, sem deixar de considerar as dificuldades de intervenção na família, é enfatizada a importância de investir na manutenção dos vínculos familiares. No último capítulo, o perigo real de morte e a ausência de políticas públicas de enfrentamento de crimes cometidos contra mulheres são considerados limites que interferem nas possibilidades de ruptura da violência doméstica.

No período compreendido entre os anos 2003 e 2005 foram disponibilizadas ao público, obras que apresentam e discutem aspectos do trabalho de psicólogos no âmbito da Justiça e da Lei. Dentre algumas obras publicadas no período destacam-se: a) Psicologia jurídica no processo civil 
brasileiro, de Denise Maria Perissini da Silva, cujo objetivo é apresentar aspectos relativos ao Direito de Família e ao Direito da Infância e da Juventude com ênfase na prática dos profissionais da Psicologia e do Direito; b) Psicologia jurídica: implicações conceituais e aplicações práticas, de Maria Adelaide de Freitas Caires, que apresenta a sistematização da experiência profissional da autora, com perícias psicológicas e questionamentos dela decorrentes, e c) Temas em Psiquiatria Forense e Psicologia Jurídica, produzido sob a coordenação de Sérgio Paulo Rigonatti, com textos sobre aspectos históricos da prática forense, etiologia do comportamento criminoso, papel da família na gênese e na recuperação do delinqüente e violência doméstica, entre outros.

Em setembro de 2005 foi publicado o livro: $O$ trabalho do psicólogo no campo jurídico, organizado por Roberto Moraes Cruz, Saidy Karolin Maciel e Dario Cunha Ramirez, com textos relacionados à inserção e intervenção de psicólogos em organizações de Justiça. A maior parte dos trabalhos que integra a obra foi apresentada no I Seminário de Psicologia Jurídica do Estado de Santa Catarina e é fruto da produção teórica do Grupo de Estudos de Psicologia Jurídica do referido Estado. Tais livros, assim como Psicologia Jurídica no Brasil, publicado em 2004, cada qual com suas especificidades, formam um conjunto de textos que possibilita o contato com as rotinas, desafios e limitações decorrentes das intervenções de psicólogos no contexto jurídico e contribui com a produção do conhecimento na interface das ciências psicológica e jurídica.

A obra interessa a estudantes, professores e demais estudiosos dos domínios psicológico e jurídico. A linguagem acessível proporciona fluidez na leitura e facilidade no entendimento dos conteúdos apresentados. Estes, por sua vez, estimulam a formulação de perguntas acerca dos processos de formação de profissionais, das competências necessárias para atuação no contexto jurídico, além de outras indagações com potencial para transformação em problemas de pesquisa e, conseqüentemente, em produção de conhecimento científico.

O livro reúne artigos resultantes de produções criteriosas, apresentadas de forma clara, sem deixar de considerar dificuldades teóricas e práticas do cotidiano dos psicólogos jurídicos. Sua publicação contribui com a produção do conhecimento científico, uma vez que auxilia a compreender os processos de interação humana e suas relações com o mundo jurídico.

\section{Referências}

Brandão, E. P. \& Gonçalves, H. S. (2004). Psicologia jurídica no Brasil. Rio de Janeiro: Nau.

Brasil (2002). Código Civil. Lei 10.406 de 10.01.02

Brasil (1990). Estatuto da Criança e do Adolescente. Lei 8.069 de 13.07.90.

Caires, M. A. F. (2003). Psicologia jurídica: implicações conceituais e aplicações práticas. São Paulo: Vetor.

Cruz, R. M.; Maciel, S. K. \& Ramirez, D. C. (Orgs.) (2005). $O$ trabalho do psicólogo no campo jurídico. São Paulo: Casa do Psicólogo.

Rigonatti, S. P. (Org.) (2003). Temas em Psiquiatria forense e Psicologia jurídica. São Paulo: Vetor Editora PsicoPedagógica.

Silva, D. M. P. (2003) Psicologia jurídica no processo civil brasileiro. São Paulo: Casa do Psicólogo.

Recebido em 04.10.2005

Primeira decisão editorial em 24.11.2005

Versão final em 21.12.2005

Aceito em 04.04.2006

\section{CONGRESSO INTERNACIONAL DE PSICOPATOLOGIA FUNDAMENTAL E VIII CONGRESSO BRASILEIRO DE PSICOPATOLOGIA FUNDAMENTAL}

Data: 7 a 10 de setembro de 2006

Local: Universidade Federal do Pará

Belém - PA

Informações e inscrições

www.psicopatologiafundamental.org 